\title{
Factors Influencing Learner Attitudes Toward E-learning and Development of E-learning Environment Based on the Integrated E-learning Platform
}

\author{
Ding Aixia and Dan Wang
}

\begin{abstract}
With the development of Multimedia and networking as well as their extensive application in educational field, the learning environment extends beyond the classroom and establishing an E-learning culture is seen as essential to the future of higher education and the facilitation of life long learning. In this paper, we present an overview of E-learning environment that we have implemented using the integrated E-learning platform. In order to present a picture of E-learning environment of universities and students' attitudes toward it, a survey was conducted to investigate the critical factors affecting learners' satisfaction in e-learning environment. The findings presented that the perception of e-learning is positively influenced by its flexibility in knowledge management, time management and widening access to information. Moreover, an integrated E-learning platform, providing many web-based, multi-platform tools, is introduced based on knowledge management. We present the architecture of the platform, and then try to analyze the development environment and application systems related to the integrated platform. The user evaluation and the application effects are also analyzed.
\end{abstract}

Index Terms-E-learning, Integrated platform, E-learning environment, learner satisfaction, Attitude.

\section{INTRODUCTION}

E-learning is the use of telecommunication technology to deliver information for education and training. With the global communication and Internet connection speed, web content has grown richer and more interactive for users. It has certainly changed the way we acquire knowledge. Learning is no longer the same as before that limited to lessons in the classroom. E-learning is seen as a future application worldwide as it promotes life long learning by enabling learners to learn anytime and anywhere. This paper discusses the findings from a study investigating the factors that influence the utilization of E-learning.

And E-learning platform is becoming a field of research that deserves the attention of the teaching and research community, so more and more universities have been invested a huge amount of resources to implement their e-learning platform or environment [1]. However, the traditional E-learning system, which is used to deliver and management contents and learning, can no longer provide the processes required to sustain the interest of a student as he learns. As a result many e-learning facilities ended up as

Manuscript received August 15, 2011; revised August 28, 2011.

A. X. Ding is with the Faculty of Foreign Language, Ningbo University, Ningbo, China (phone: 86-574-87600334; e-mail: dingaixia@nbu.edu.cn).

W. Dan is with the Network Center, Ningbo University, Ningbo, China (e-mail: danwang@nbu.edu.cn). merely file servers [2].

Recently, blogs and personal pages have recently emerged as popular uses of the Internet for people to learn, share and interact with people from all walks of life across the world. And with the popularity of E-learning increasing among academic and training institution, learning and knowledge building have become a highly integrated and interactive global process. For this reason, integrated E-learning platform appears as a result of the efforts to make a step forward towards a more effective and quality. E-learning presents an opportunity to enhance learning as to create environments where students and teachers can share knowledge. It is very important to design an efficient E-learning platform for teaching, learning, resources, and administration [3-4].

From the beginning of this century, Ningbo University has established many web-course learning systems, teaching affairs management systems, roll management systems and digital library systems. But the E-learning environment has not been built up, because these systems related to E-learning are mutually independent with inconvenient software. Teachers are more willing to build a network classroom based on a personal website with security risks for interaction with students [5-6].

In this paper, we present an integrated e-learning environment where students can share and operate these resources at any time. The core management platform is filled with any applications and tools related to e-learning. The platform supports the creation of a self-learning and innovative learning environment with the aim of providing new ways of user interaction and data representation in a knowledge-based environment in which teachers and students cooperate to share knowledge when each one has his or her relevance within the entire learning process.

The rest of this paper is organized as follows. Firstly, the analysis and statistical results of the survey with respect to the critical factors affecting learner attitude toward E-learning are reported. Secondly, some details of the architecture of the e-learning platform system are described. Thirdly, application environment of the integrated E-learning is then presented. Fourthly, application systems of the platform are introduced. Fifthly, the platform integration with other systems is described. Sixthly, the application effects of the platform are analyzed. Lastly, this paper concludes and presents areas for future work and improvement.

\section{INVESTIGATION OF THE CRITICAL FACTORS INFLUENCING LEARNER SATISFACTION}

E-learning is emerging as the new paradigm of modern 
higher education. Although e-learning environment are popular, there are many students who stop their online learning after their initial experience. And students' initial perceived satisfaction with technology-based E-learning will determine whether they will use the system continually. However, there is minimal research on college students' attitudes toward the E-learning environments. One study was conducted at Ningbo University to investigate the critical factors influencing students' satisfaction in E-learning. The purpose of the quantitative study was to gain an overall picture of all the subjects related to E-learning environment.

\section{A. Participant}

128 college students from different majors of Ningbo University are asked to answer questionnaires for investigating their perceptions, of whom 79 are females and 49 are males with an age ranged from 19 to 22 . The participants were invited to respond to the same questionnaire at the end of the third semester. The student background survey revealed that most participants were drawn to this by virtue of their personal interests in both communication and computer skills.

\section{B. Research instruments}

Defining actual satisfaction from the use of learning environments is a meaningful matter. Previous research done under different task environment has suggested a variety of factors affecting user satisfaction with e-learning environment. Exploration of literature highlighted common perspectives influencing e-learning, such as levels of computer skill, computer accessibility and availability, usability of the e-learning platform and time flexibility [7]. The research utilized a combination of survey questionnaire and literature review. The questionnaire consisted of 10 questions including a range of single, multiple choice and attitude statement questions. The questions were selected to explore the positive and negative factors of students' experiences and to assess their satisfaction of the E-learning environments. The questionnaire was an adaptation of others literature.

After a period of application and practice, a total of 128 questionnaires were issued, and 121 were recovered, of which 115 were valid with $100 \%$ effective rate.

\section{Findings and dsicussion}

After statistical analysis, the results, as shown in Table I , demonstrate that learners have very positive perceptions toward using E-learning environment. Many students agree with the statement that e-learning has stimulated the interest of learners and improved learning efficiency. Nevertheless the descriptive evidence supported these results with a higher proportion $(27.4 \%)$ of comments indicating the negative impact lf e-learning has on user learning.

Table $I I$ revealed that e-learning course quality, integrated e-learning platform function, perceived ease of use and learners computer literacy and skill are the critical factors affecting students' perceived satisfaction. Together, these four factors are able to explain $83.8 \%$ of the variance of learner attitude.

As expected course quality and e-learning platform design are the most important concern in this e-learning environment. Ease and flexibility of platform are viewed as an important factor in e-learning environment. At all time, system administrators should ensure all platform functionalities are available.

Although the computer is popular among the young of China, students' computer skill also hampers their satisfaction. Helping students build their confidence in using computers will make e-learning more enjoyable.

\section{DEVELOPMENT OF THE E-LEARNING ENVIRONMENT}

In the establishment of e-learning environment, the most important idea is to start by defining the instructional goal and then classifying learning contents that are best equipped to build the learning environment. For designing effective E-learning environment, $\operatorname{Liaw}(2005)$ suggested that autonomous learning, Multimedia environments and instructor-led learning create effective e-learning environment [8].

The fundamental environment components for e-learning systems include the whole information system related to e-learning environment. We present our integrated E-learning platform focusing the attention on the design, development and implementation. The platform consists of several management functions including data management system, learning management system and curriculum contents management system.

\section{A. Architectural design of the platform}

The integrated E-learning platform architecture is composed of four layers, namely data infrastructure layer, data collection layer, teaching service layer and application layer, as shown in Fig.1.

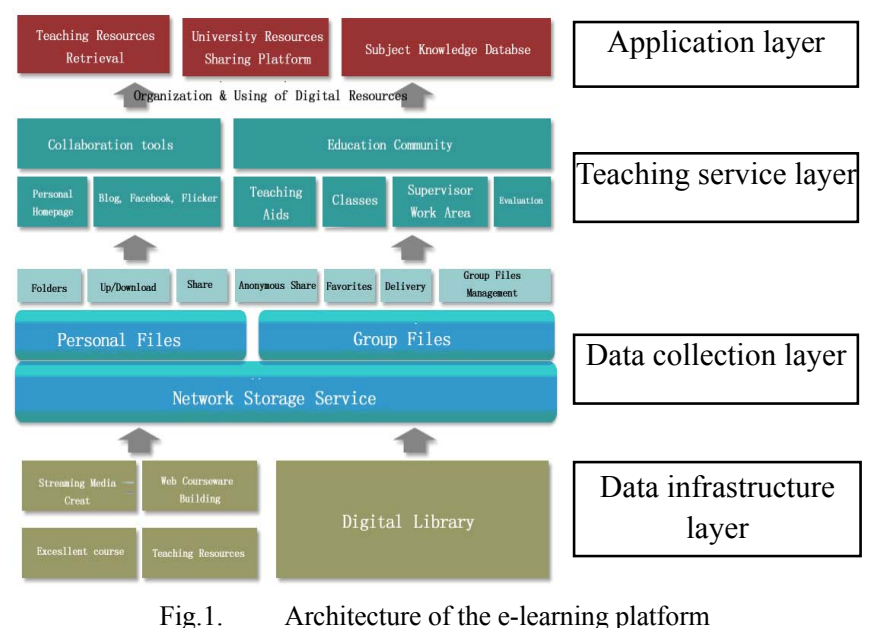

The infrastructure layer, made up of all the basic network support environment devices and systems, is responsible for providing some software tools for teachers to complete WEB courseware and streaming media courseware, which can be very convenient and effective for accumulating teaching resources.

The network storage services based on the collecting layer of digital resource are established to provide document retrieval services for teachers and teaching teams. And the resources can be shared and collected by residing in an E-learning system or a learning management system and can be used to store and manage its content. 
It provides a sharing platform with a set of software tools for teachers and students to publish a variety of information through personal home pages or blogs. The design makes use of standard existing hardware and software so that new computing resources can joint the platform easily to reduce cost and complexity.

In addition to teaching outside the classroom, the daily interaction between teachers and students is also essential. The purpose of the establishment of classes and mentors' work areas in the teaching service layer is to meet the needs of students and teachers interact daily. Extra-curricular learning and sharing content between the groups are recorded, such as notification, discussion, job, courseware, documents and web conferencing. And the school evaluation system is used to monitor and control the teaching process.

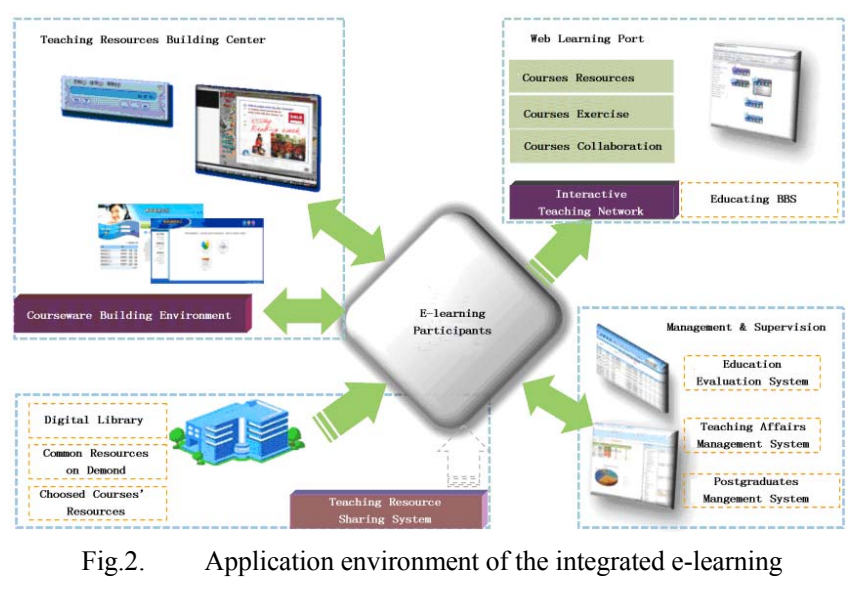

The function of education application layer is to enhance the teaching service to the university level by accumulating digital resources and teaching knowledge.

Figure 2 shows the integrated E-learning environment of Ningbo University, which is divided into five parts, Teaching Resources Building Center (TRBC), Web Learning Port (WLP), Teaching Resources Sharing System (TRSS), Management \& Supervision System (MSS) and E-learning Participants System (EPS).

TRBC takes central place in our hierarchical model and gives teachers various tools to build teaching contents. Students and learners can access WLP to get the teaching contents and involve online discussion board with their instructors and peers upon their own convenience. TRSS give well-structured information support to teachers and students. For the admin personnel, they act on administration roles of online matters via the MSS.

With the flexible and easily extensible model which is constructed in a way that its five main parts are strongly independent one from another. Thus, any changes or extensions of one of them do not reflect in others one. It allows easily to add new requirements and to improve the adaptation engine without necessity to change the model.

\section{B. Application systems of the platform}

The integrated platform is a teaching assistant and collaborative platform to implement online teaching and learning use of advanced network technology. It can provide network storage space and a certain corresponding production tools for teachers and students, with which teachers can settle teaching resources, show their best courseware and exchange each other's learning experience.

With the platform teachers can use various types of resource of the sharing system, such as producing outstanding courseware in the production center, interactive teaching with students in the learning portal, and discussion and $\mathrm{Q} \& \mathrm{~A}$ in the community forum. Students can acquire knowledge from the teaching resources sharing system, and communicate with teachers and students. In addition, students can also help teachers create courseware and evaluate teachers and management. And managers can supervise and manage the process of teaching and learning.

The advantages of the platform and its features can resolve many issues and problems related to the use of current e-learning system. However, related systems included in the integrated platform are described as follows.

\section{1) Portal system}

The E-Learning Portal, sits on top of a variety of application system, is not only the unified access point for all application systems, but also the information platform where and all kinds of information from the e-learning platform can be released and collected. Information integration and releasing, application integration, single sign-on, content customization and personalized services are included in the portal to demonstrate the application information of the digital learning platform for teachers and students, which can effectively fill the gaps between various applications and also provides many valuable added features, such as security, search and so on.

\section{2) Virtual Classroom System}

The virtual classroom system, which enables inter-school academic lectures and video conferencing, has the function of interactive video teaching. When teachers go abroad on a business or a meeting, remote instruction between teachers and students, for example, video exchange, text dialogue, voice answering, PPT presentations, desktop sharing, document and file transfer, etc., will be achieved through the Internet-based "video class". In addition, it also has the function of simultaneously recording class content that can be automatically changed into courseware for students to download.

\section{3) Learning Management System}

Generally, learning management system includes curriculum resources management, curriculum training, curriculum collaboration, a variety of academic information and student data management.

\section{4) Resource Management System}

Resource management system allows teachers to achieve issuing and collating of teaching resources. In this way, accumulating, sorting and sharing of curriculum resources will become easier. Resource management system is connected with the digital library of Ningbo University so that students can retrieve and use digital resources more easily.

\section{5) Bulletin Board System}

BBS in this platform has a "campus community" feature. Using this system, faculty or department managers can not only issue notices and manage information resources, but also design a home page with faculty / department's features. In addition, BBS can also be used for a certain unit or groups of students to improve the efficiency of the daily 
work.

6) Teaching Evaluation System

The teaching evaluation system includes teaching assessment subsystem, student learning assessment subsystem and teaching management evaluation subsystem. The purpose is to evaluate the performance of teachers, students and administrators in the integrated digital learning platform.

\section{7) Multimedia Rrecording System}

In order to construct the Multimedia recording system, many recorded components have been added to the original equipment in the school multi-media classrooms, conference rooms and lecture halls. Without teacher intervention, teaching process, including teachers, audio, video, and screen and writing on the blackboard, has been recording into courseware directly. Recorded Multimedia files can be easily embedded in the Web pages and courseware.

\section{Integrated with other systems}

The platform is integrated with the unified authentication platform. The user name and password of the E-Learning platform are consistent with the school's unified authentication platform.

After integrated with the common data platform, teachers, students, organizations and other basic information of the E-Learning platform are extracted directly from the common data platform.

Digital library resources and services are integrated with the E-Learning platform to build all kinds of teaching test database.

Integrated with the Educational Management System, courses, classes and other information of the E-Learning platform are taken from the educational management system.

E-Learning platform are integrated with the Graduate Management system to ensue that the graduate courses, instructors and other information are the same with that of the Graduate Management system.

TABLE I. STUDENTS' ATTITUDES TOWARD E-LEARNING ENVIRONMENT

\begin{tabular}{|c|c|c|c|c|c|}
\hline No. & Question & Strongly agree & Agree & Disagree & Indifferent \\
\hline 1 & The e-learning environmentenable us to access information and lear when we want & $28.3 \%$ & $63.6 \%$ & $3.2 \%$ & $4.9 \%$ \\
\hline 2 & Compared to traditional learning, e-learning makes me productive at my study & $19.8 \%$ & $58.4 \%$ & $12.3 \%$ & $9.5 \%$ \\
\hline 3 & The environment can enhance exchange and communication between the teachers and students & $26.3 \%$ & $52.6 \%$ & $11.6 \%$ & $9.5 \%$ \\
\hline 4 & The e-learning requires technical ability & $11.3 \%$ & $39.6 \%$ & $28.7 \%$ & $21.4 \%$ \\
\hline 5 & I feel confident that e-learning environment can increas interest of learners & $17.9 \%$ & $54.3 \%$ & $20.6 \%$ & $7.2 \%$ \\
\hline 6 & The e-learning is only advisable for people with a lot of computer knowlege & $19.6 \%$ & $21.8 \%$ & $73.5 \%$ & $15.1 \%$ \\
\hline 7 & E-learning is time consuming and let me feel psychological stress very greatly & $8.8 \%$ & $18.6 \%$ & $57.8 \%$ & $14.8 \%$ \\
\hline 8 & Sufficient resources would be mproved in the e-learning environment & $29.3 \%$ & $54.7 \%$ & $10.7 \%$ & $5.3 \%$ \\
\hline 9 & It is difficult for me to become skillful at using the integrated e-learning platform & $12.8 \%$ & $36.1 \%$ & $40.0 \%$ & $8.9 \%$ \\
\hline 10 & I am disappointed with the way the e-learning work out to nteractwith other students & $24.6 \%$ & $53.1 \%$ & $19.8 \%$ & $2.5 \%$ \\
\hline
\end{tabular}

\begin{tabular}{|c|c|c|c|c|c|c|c|c|c|}
\hline Factor & $\begin{array}{c}\text { Computer } \\
\text { literacy } \\
\text { and skill } \\
\end{array}$ & $\begin{array}{c}\text { Computer } \\
\text { availability and } \\
\text { accessibility }\end{array}$ & $\begin{array}{l}\text { Platform } \\
\text { Function }\end{array}$ & Training & $\begin{array}{c}\text { Instructor } \\
\text { attitude }\end{array}$ & $\begin{array}{l}\text { Perceived } \\
\text { ease of use }\end{array}$ & $\begin{array}{c}\text { E-learning } \\
\text { course quality }\end{array}$ & $\begin{array}{c}\text { E-learning } \\
\text { platform } \\
\text { flexibility }\end{array}$ & $\begin{array}{c}\text { Tota } \\
1\end{array}$ \\
\hline $\begin{array}{l}\text { Student } \\
\mathrm{S}(\%)\end{array}$ & $16.5 \%$ & $4.6 \%$ & $22.3 \%$ & $11.9 \%$ & $12.2 \%$ & $18.7 \%$ & $26.3 \%$ & $13.5 \%$ & $\begin{array}{c}100 \\
\%\end{array}$ \\
\hline
\end{tabular}

\begin{tabular}{|c|c|c|c|c|c|c|c|c|}
\hline & & & & & & & & \\
\hline Learning Activity Classification & Search & Browse & Read & Writing & Administration & Communication & Service & Total \\
\hline Participant number & 636 & 2059 & 744 & 177 & 99 & 406 & 64 & 4185 \\
\hline$\%$ & $15.2 \%$ & $49.2 \%$ & $17.8 \%$ & $4.2 \%$ & $2.4 \%$ & $9.7 \%$ & $1.5 \%$ & $100 \%$ \\
\hline
\end{tabular}

Through tags students can quickly find a common interest with their peers, discussing topics of interest and sharing of resources.

With the digital resources of the platform, teachers and students can receive the resources conveniently and need not look at every page of a web. Moreover, learners can maintain control of their own learning to find problems and correct their own learning goals.

The integrated E-learning platform based on network promote personal knowledge accumulation and group knowledge sharing, which can improve learning efficiency, facilitate the innovation of knowledge, and then enhance the core competitiveness of individual and group.

\section{Statistical Learning Activities}

Student learning activities on the platform can be divided into search, browse, read, writing, administration, communication and service. As shown in table III, students engaged in the platform mainly for cognitive learning activities, with small part of students for meta-cognitive and emotional exchanges.

\section{CONCLUSION}

Online E-learning is an effective alternative to traditional face-to-face education. Compared with school education, web-based education makes a great change in its space, time, method of teaching and learning. Many institutions implement E-learning environment to meet students' needs. Since E-learning is conducted using the Internet and World Wide Web, the learning environment becomes more complicated [9].

The users' survey results of the students' attitude show that the vast majority of users are satisfied with the e-learning environment. And the implications from this research highlight the challenge for educators in understanding, developing awareness of and identifying strategies to manage these factors. A central role was identified for e-learning including proposals to equip all students with the skills and resources to access learning opportunities and share knowledge at a time and place that fits their lifestyle.

The integrated E-learning platform is considered to be a 
good way to support teaching and learning activities based on knowledge management. In this paper, we have presented an integrated E-learning platform interacting and participating in the educational process, which can be the answer to the many challenges faced by today's E-learning administrators and implementers. The goal is to build a comprehensive teaching, research, service, innovation and network interaction platform through further integration of the school and outside of teaching, research, country, industry, policy, demand and other digital resources and learning courseware.

Although this research represents an effort to incorporate elements of E-learning environment, there are some limitations. Therefore, research efforts to improve the features of the E-learning environment will be continued. And we believed that the services and functions would be continuously extended to cover users' requirements.

\section{REFERENCES}

[1] B. Bontchev, D. Vassileva, B. Chavkova, and V. Mitev, "Architectural Design of a Software for Adaptation Control in the ADOPTA E-learning Platform," Proc. ACM Symp. Interational Conference on Computer Systems and Technologies (COMPSysTech 09), ACM press, Jun.2009, pp. 1-6, doi: 10.1145/1731740.1731767.
[2] F. D. Cerbo, G. Dodero, and L. Papaleo, "Integrating a Web3D Interface into an E-learning Platform," Proc. ACM Symp. International Conference on Web 3D Technology (Web3D 10), ACM Press, Jul. 2010, pp. 83-92, doi: 10.11451/1836049.1836062.

[3] A. S. Drigas, A. Tagoulis, P. Kyragianni, P. Nikolopoulos, D. Kalomoirakis, and et al., "An E-learning Platform for Multiform and Interactive Education of Scholars in Greek Paleography," Proc. ACM Symp. International Conference on Distance Learning and Web Engineering, ACM Press, Aug. 2005, pp. 90-94.

[4] B. J. Zimmerman, "Investigating Self-Regulation and Motivation: Historical Background, Methodological Developments, and Future Prospects," American Educational Research Journal, vol. 45, May 2008, pp. 166-184, doi: 10.3102/0002831207312909.

[5] Y. H. Zhen, S. X. Hua, and L. L. Hua, "PLC Experimental Teaching Platform Based on Configuration Technology," Journal of Ningbo University (NSEE), vol. 23, Jan. 2010, pp. 42-45.

[6] Z. Y. Ying, Z. S. Dong, and D. Xin, "ZigBee-based Design of Data Acquisition System," Journal of Ningbo University (NSEE), vol. 22, Sep.2009, pp. 313-316.

[7] H. McVeigh, "Factors Influencing the Utilisation of E-learning in Post-registration Nursing Students," Nurse Education Today, vol. 29, Jul. 2008, pp. 91-99.

[8] S. S. Liaw, H. M. Huang, and G. D. Chen, "Surveying Instructor and Learner Attitudes Toward E-learning," Computers \& Education, vol. 49, Aug. 2005, pp. 1066-1080.

[9] P. C. Sun, R. J. Tsai, G. Finger, Y. Y. Chen, and D. Yeh, "What Drives a Successful E-learning? An Empirical Investigation of the Critical factors Influencing Learner Satisfaction," Computers \& Education, vol. 50, Nov.2006, pp. 1183-1202 